\title{
Failure to Communicate: Inefficiencies in Voluntary Incentive Programs for Private Forest Owners in Michigan
}

\author{
Mark D. Rouleau ${ }^{1}$, Jennifer F. Lind-Riehl ${ }^{1,2}{ }^{\text {, Miranda N. Smith }}{ }^{1}$ and Audrey L. Mayer ${ }^{3, *}$ \\ 1 Department of Social Sciences, Michigan Technological University, Houghton, MI 49931, USA; \\ mdroulea@mtu.edu (M.D.R.); jflind@mtu.edu (J.F.L.-R.); mnaho@mtu.edu (M.A.) \\ 2 Department of Entomology, University of Wisconsin-Madison, Madison, WI 53706, USA \\ 3 School of Forest Resources and Environmental Science, Michigan Technological University, \\ Houghton, MI 49931, USA; almayer@mtu.edu \\ * Correspondence: almayer@mtu.edu; Tel.: +1-906-231-2864
}

Academic Editors: Thomas J. Straka and Timothy A. Martin

Received: 27 July 2016; Accepted: 1 September 2016; Published: 6 September 2016

\begin{abstract}
Coordinating forest management across thousands of nonindustrial private forest (NIPF) owners is a difficult yet necessary task for state land management agencies. Voluntary Incentive Programs (VIPs) can coordinate the decentralized activities of these owners in return for services or financial incentives. However, many VIPs typically have low enrollment. Our study investigates the implementation of VIPs to increase forest management coordination among NIPFs in Michigan. We present findings from 20 semi-structured interviews with leaders of state and local land management organizations, and government officials at state natural resource agencies, and contrast their answers with those recorded from 37 interviews of NIPF owners regarding their knowledge and attitudes toward VIPs. Our interviews highlight a critical disconnect between NIPF owner motivations and VIP incentives, as well as misallocated resources for VIP promotion by state agencies, driving low enrollment. At the core, low enrollment in VIPs is generated by inadequate communication between NIPF owners and program managers, along with distrust of government agency objectives. Viewing managers as "street level bureaucrats", civil servants whose job discretion is impacted heavily by available resources, may increase our understanding of the issues plaguing VIPs and help identify improvements to VIP design and implementation.
\end{abstract}

Keywords: landowner programs; Michigan; family forests; nonindustrial private forests; program managers; street level bureaucrats; policy implementation

\section{Introduction}

Individual private landowners greatly impact regional ecosystems at multiple scales [1]. Therefore, it is critical that land managers coordinate the management decisions of often thousands of non-industrial private forest (NIPF) owners to achieve broad forest management and conservation goals [2]. Such coordination is important for addressing a wide variety of forest conservation concerns, from controlling the spread of invasive species, to mitigating ecological responses to climate change, and even ensuring adequate provision of economic forest resources such as timber and pulp [3-7]. However, large-scale coordination is difficult for state land management agencies, particularly in a regulatory environment that strongly favors the land use autonomy of NIPF owners. This is why many land management agencies now use voluntary incentive programs (VIPs) to "encourage" the adoption of informed land management practices on private lands. Given that private landowners voluntarily participate in VIPs, this also makes it possible for regulatory agencies to minimize their oversight 
burden because compliance results from interest alignment rather than agency coercion [8,9]. Thus, in theory, VIPs can bridge an important regulatory gap but, in practice, widespread under-enrollment often prevents VIPs from fulfilling their potential [8,9].

The VIP approach is popular with landowners because it uses incentives rather than coercion to motivate actors to voluntarily commit to management activities to achieve policy targets e.g., [10]. Incentives such as informative materials and technical assistance help owners overcome implementation barriers such as a lack of "know how" or access to technology to begin or maintain management activities beneficial to a given conservation goal. Such incentivization works best for owners already "aligned" to the management goal in question but, lacking a critical mass of "aligned" NIPF owners, VIPs can also use financial rewards, primarily in the form of property tax deductions, to encourage owners to abandon conflicting management preferences. Financial incentivization greatly increases program costs when owners require high monetary compensation to participate. Thus, it is important that VIPs pay particular attention to the messaging of their program goals to take advantage of already aligned management conditions [11,12].

Our study on VIPs also falls into the broader literature on NIPF owners. According to [13], the behavior of NIPF owners is one of the most studied topics in forest economics (although see [14]). Yet, according to [15], there are many questions left unanswered, such as how (or to what extent) decentralized land management efforts impact management practices. They suggest that further research is needed to determine how incentives and interactions between NIPF owners and land management organizations encourage NIPF owner behaviors and intentions to align with the policy goals of resource management agencies. Our research explores this issue in great detail to explain why the problem of VIP under-enrollment persists in the Western Upper Peninsula (UP) of Michigan, an area of the United States that is a logical fit for VIP management. We first describe the history and current use of VIPs in the Western UP, and then describe key disparities between interpretations of VIPs by program managers and forest owners as revealed in interviews conducted with both groups. We then explain how these disparities might be rectified to improve communication between managers and landowners with assistance from the "street level bureaucrat" literature, explaining how discretion and a lack of resources influences policy implementation by government agents [16,17]. First described by Lipsky in 1980 [16], street level bureaucrats are public servants whose daily decisions, in the aggregate, have a large impact on how the policies within their agency's purview are implemented. Thus whether a policy is successful or meets agency goals is due in large part to the discretion and actions of these public servants.

\section{VIPs in the Western UP}

The Western UP is an area of the United States that is about $80 \%$ forested and sparsely populated (average population density of 7.5 people per $\mathrm{km}^{2}$ ) [18]. NIPF owners own roughly one-third of the forestland in the Western UP with the remaining two-thirds divided nearly evenly between public (national and state forests) and private industrial forests. This ownership composition means that NIPF owners play a critical role in regional forest management. The first use of VIPs to achieve NIPF owner coordination dates back to the Western Upper Peninsula Forest Improvement District (WUPFID) created in the Forest Improvement Act of 1980. The WUPFID only operated from 1986 to 2004, but in this short time it achieved the greatest enrollment success of any VIP ever to operate in the area. It used $\$ 1.6 \mathrm{M}$ in state funds to incentivize NIPF enrollment in the program through no-cost technical services. At its peak, the WUPFID had enrolled 2000 parcels owned by roughly 900 owners $(25 \%$ of the parcels were legally required to be NIPF lands); the enrolled forests included almost 20,000 acres (roughly 1.5\% of the eligible NIPF acreage). However, the State cut funding to the WUPFID in 1994 because lawmakers wanted the WUPFID to become financially independent. This encouraged the WUPFID to shift most of its efforts to market-oriented management interests (especially timber and pulp production), and eventually the program ended as local mills closed $[18,19]$. Current VIPs in the 
area have yet to achieve the enrollment rates of the WUPFID, and continue to struggle with the same political controversies that forced the closure of this once successful program.

The major VIPs currently operating in the Western UP are either Federal programs implemented at the State level or State programs implemented at the State or local level (Table 1). All of these programs are much narrower in scope than the WUPFID so they are less likely to have a large impact on regional forest conditions without cross-program coordination. For example, the most popular program with the highest enrollment rate in the Western UP is the Michigan Department of Natural Resources' (DNR) Commercial Forest Reserve. The Commercial Forest Reserve uses tax reductions to encourage owners to manage forests for the production of marketable forest products (primarily timber and pulp). This goal can and does often conflict with the management goals of other non-market oriented VIPs, such as the Michigan DNR's Landowner Incentive Program. The Landowner Incentive Program seeks to encourage wildlife habitat protection and improvement activities on NIPF lands using financial and technical assistance incentives. The Commercial Forest Reserve and Landowner Incentive Program objectives are difficult to achieve in parallel, especially without adequate program coordination. For all VIPs, enrollment requires that forest owners submit a management plan that is approved by the state, and state foresters can randomly check these plans for compliance. Owners who do not comply with their management plan can be fined. In this sense, when owners enroll in a VIP they are exchanging some of their land use rights for lower property taxes or other incentives, for the duration of the enrollment contract. We explore below how this current VIP structure in the Western UP contributes to less than ideal management coordination and higher than expected program under-enrollment.

Table 1. Organizational representation of interviewees, currently operating Voluntary Incentive Programs (VIPs) in Michigan, and their incentives.

\begin{tabular}{|c|c|c|}
\hline Organization & VIP & Incentives \\
\hline \multicolumn{3}{|c|}{ Federal Program Implemented at the State Level } \\
\hline USDA/NRCS & $\begin{array}{l}\text { Wildlife Habitat Incentive } \\
\text { Program }\end{array}$ & Cost-sharing for habitat restoration \\
\hline $\begin{array}{l}\text { USDA/Farm } \\
\text { Service Agency }\end{array}$ & $\begin{array}{l}\text { Biomass Crop } \\
\text { Assistance Program }\end{array}$ & $\begin{array}{l}\text { Cost-share payments for up to } 15 \text { years of } \\
\text { woody crops }\end{array}$ \\
\hline USDA/NRCS & $\begin{array}{l}\text { Environmental Quality } \\
\text { Incentive Program }\end{array}$ & $\begin{array}{l}\text { Financial and technical assistance for } \\
\text { implementing conservation practices }\end{array}$ \\
\hline USDA/NRCS & $\begin{array}{l}\text { Conservation } \\
\text { Stewardship Program }\end{array}$ & $\begin{array}{l}\text { Financial and technical assistance for forest } \\
\text { management plans }\end{array}$ \\
\hline $\begin{array}{l}\text { NRCS/Farm } \\
\text { Service Agency }\end{array}$ & $\begin{array}{l}\text { Emergency Forest } \\
\text { Restoration Program }\end{array}$ & Cost-sharing up to $75 \%$ of restoration costs \\
\hline \multicolumn{3}{|c|}{ State Program Implemented at the State or Local Level } \\
\hline MDNR & $\begin{array}{l}\text { Commercial Forest } \\
\text { Reserve Program }\end{array}$ & Property tax reduction \\
\hline MDNR & Forest Stewardship Program & $\begin{array}{l}\text { Cost-sharing for forest management } \\
\text { plan development }\end{array}$ \\
\hline $\begin{array}{l}\text { MI Dept. of Agriculture } \\
\text { and Rural Development }\end{array}$ & Qualified Forest Property & School tax exemption \\
\hline MDNR & $\begin{array}{l}\text { Landowner } \\
\text { Incentive Program }\end{array}$ & $\begin{array}{l}\text { Technical and financial assistance for wildlife } \\
\text { habitat restoration }\end{array}$ \\
\hline $\begin{array}{l}\text { MI Forest } \\
\text { Products Council }\end{array}$ & $\begin{array}{l}\text { Michigan Sustainable } \\
\text { Forestry Education Program }\end{array}$ & Educational certification on sustainable forestry \\
\hline
\end{tabular}




\section{Methods}

Our study used semi-structured interviews to gain a detailed understanding of the role and implementation of VIPs in the Western UP. We chose this method because our study is necessarily exploratory in nature and a thorough contextual understanding of the decision-making and policy implementation dynamics underlying our topic is commonly accepted to be a prerequisite to further qualitative (e.g., larger scale interviews or surveys) or quantitative analysis [20,21]. Also, given the small number of land management organizations in the region, it is possible to more accurately represent their views in rich detail through qualitative methods. Finally, although our sample size is insufficient to infer from the perceptions of our sampled NIPF owners to the full population, our goal instead was to purposively sample individuals to outline the range of existing owner perceptions in the area.

In the summer of 2013, we conducted semi-structured interviews with leaders of prominent state and local land management associations and program managers at state agencies (see Supplemental Materials for protocol and interview questions). We then compared their views on VIPs to those of a purposeful sampling of 37 Western UP NIPF owners interviewed concurrently. The research design and major findings from our interviews with NIPF owners have been previously published in another work [22]. The goal of the current paper is to contrast these findings with our land management organization interviews to identify existing gaps between NIPF owner intentions and VIP program goals and implementation through outreach efforts.

We attempted to interview as many leaders as possible from all organizations with a land management mission active in our study region. We interviewed leaders or program managers from the following organizations: US Fish and Wildlife Service, National Resources Conservation Service, Trout Unlimited, Michigan Department of Agriculture, Michigan Department of Natural Resources, Michigan Farm Services Agency, Michigan State University Extension Office, Michigan Forest Association, Michigan Association of Timbermen, Michigan Forest Products Council, Upper Peninsula Land Conservancy, and several local consulting foresters who play a prominent role in providing services to private forest owners in the region [23]. We chose these organizations because they are highly likely to be in contact with NIPF owners regarding forest management issues and are in a professional position to actively promote VIPs.

Our work resulted in a total of 20 separate "key informant" interviews. Some interviewees represented more than one organization simultaneously while many interviewees were also responsible for promoting more than one VIP (e.g., if different employees managed multiple VIPs at an agency). Each interviewee was either an official program manager or a "key informant" with professional responsibilities that included advocating for and/or implementing one or more VIPs in the Western UP. Interviews were semi-structured, mostly open-ended questions, with prompts to discuss four key issue areas: the characteristics of the interviewee's organization (including organizational goals and relevant geographic area); the responsibilities of the interviewee's position; the manner and frequency of contact between the organization and landowners (including mechanisms and direction of information flow); and the level of involvement in and support for VIPs (both the interviewee and the organization).

Our interviewer's audio recorded each interview, recorded text-based field notes upon completion of each interview, and then transcribed all interviews using HyperTranscribe transcription software. Transcriptions were analyzed using the qualitative data analysis software Hyper Research. The analysis process began with the creation of a key themes codebook, which required three members of our research team to independently identify and then collectively cross-validate common themes discussed in all interviews (the same method was used for the NIPF owner interviews cited above). Each theme was then assigned a unique code to be used to flag all instances in every transcript in which a specific theme was discussed (See Supplemental Materials for themes and codes). We coded interviews with program managers first to identify what they believed were the strengths and weaknesses of their programs, and then compared these to the coded interview data of NIPF owners. This order was partially motivated by the considerable number of NIPF owners who had never heard of any VIP. 
Starting our coding with program managers instead of NIPF owners ensured the development of the most complete set of codes possible. The quotes presented in the next section were all chosen to highlight themes that had a high frequency distribution or demonstrate insights on themes most relevant to current VIP literature.

\section{Findings and Discussion}

The most common themes that emerged from our interviews with management agencies related to: (1) inadequate resources for agency staff and incentive funds, (2) inadequate and inefficient outreach to potential NIPF owner enrollees, (3) problems navigating existing programs due to regulatory complexity, (4) the need for non-governmental proxies to simplify VIP choices and buffer NIPF owners from direct contact with government agencies perceived to be hostile to private property interests, (5) the role of and potential for conflict of interest among existing proxies, and (6) the possibility of underserved NIPF owner goals within the existing program landscape. We contrast these findings with responses from landowners within the same theme.

\subsection{Inadequate Program Funding}

The issue of inadequate program funding was the most frequently discussed topic in our VIP interviews with program managers and organizations. This is a central issue for most street level bureaucrats, who often report that they have insufficient resources to help all clients and implement policies fully and effectively $[16,17,24]$. Western UP VIPs rely almost exclusively on public revenues, and most program managers cited the low priorities given to VIPs by federal or state politicians as the source of this funding problem. For example, one agency representative claimed:

"Our legislature does not for some reason, (take) the time to realize what an important role (VIPs) play with private landowners in the DNR. And it's discouraging to me that they've cut us back so bad. And everybody's getting cut back."

In our interviews with NIPF owners, we found some sympathy for this budget constraint problem. For example, a few landowners were aware of the fact that a very small number of program managers were responsible for overseeing very large areas, mainly due to budget cutbacks affecting staffing levels at program agencies. One landowner remarked:

"Though the state is limited in personnel to watch over the program, they do look into every single complaint, they look into every single potential cut that you're going to have. There's a pre-harvest form that you have to send in, they look at that, they look at every single parcel of land that you're trying to qualify for commercial forest. So for the personnel that's out there, they're doing a super, super job, but they're clearly lacking in personnel to cover this program which is super huge. Since that (tax relief) rule changed (for one VIP in particular), there didn't need to be a whole bunch of enforcement, so I think that opened it up and probably eliminated a lot of people, or a lot of physical bodies in the program. Which, I still think they could use more, I really do. It's a big program, there's a lot in commercial forest and we have one guy in this whole half of the UP, you know. And he's a busy guy."

"There's one woman down in Lansing that does everything, every piece of property in the state of Michigan goes through her hands. And it's hard to believe that anybody can do that, but she does. And as well, (state program manager) handling the whole east side of the Upper Peninsula which is a super huge amount of land mass. Does a great job, you know, so, I guess I'm impressed with what they do with such a small staff."

Administrators rarely escape the pressures of budget constraints but it was clear that existing VIP funding limitations in Michigan were somewhat unique to the state's political environment. For example, one program manager compared Michigan's support for VIPs to that of its nearest 
neighbors, Wisconsin and Minnesota, which share similar NIPF owner compositions and land management goals:

"(T)he Wisconsin citizenry is much better educated and aware (of) the possibilities of forest management, the roles of forests, (...) and the ecology and the social structure of the state than here in Michigan ... (T)he legislature in Michigan has never, rarely (done) anything to deal with (... ) nonindustrial private forest lands ... . (M)aybe part of it is because of strong property rights advocacy in this state but whatever the reasons are, the level of awareness and the participation (... ) in Michigan is significantly less than that in Wisconsin and in Minnesota. (B)oth of those other states have had a better funded public outreach and education program over the years."

Program managers recognize the importance of interest alignment between VIPs and NIPF owners, but politics often prevents programs from establishing and strengthening this connection. This problem extends to the voters and taxpayers who drive many of these political decisions:

"I think there are opportunities out there and I think we need to sell (...) conservation to the landowners (and) to our taxpayers (... ). I think we have a disconnect with a lot of people on conserving the environment, that they can say things are good but if we're prioritizing roads or schools or other things, conservation (... ) or forest management (... ranks) lower than other priorities (...) more immediate to them. (T)hat shows the greater need to explain some (of the benefits of conservation), the conservation programs, (and our) conservation activities."

It is important to note here that this statement applies only to the general public's willingness to support VIPs, not specifically to NIPF owners' management intentions. Taxpayer support for VIPs may be low but some program managers realized that many NIPF owners appear to have pre-existing management preferences that align well with conservation-oriented VIPs in the Western UP, as the following quote highlights:

"(M)ost of the time when we talk with (NIPF owners), their goals are driven by wildlife. Even though most people up here who write plans (or) get involved in forest management (think that) economics drive the system, (...) wildife is typically the underlying goal (...). Silviculture is used as the vehicle (...) to accomplish (that goal). Unfortunately ... the people who write those plans, especially from (the) private industry standpoint, ( . . ) don't have a wildlife background. So (the Landowner Incentive Program is) providing kind of a unique (... ) niche in that respect, giving them direct wildlife guidance. It was (a) good program but it was soft money (... ). The grant went away two years ago and (now our program status is unclear)."

While economic incentives were important to almost all of the forest owners with land enrolled in VIPs, financial incentives were much less important to owners who were not participating in VIPs [22]. For example, an owner with VIP-enrolled property stated:

"It comes down to economics. You know, some of the stuff I do is not economically feasible, but for aesthetics, for the enjoyment of it, it's not always about money. But money's a heck of a motivator for a lot of people, including me."

This stands in contrast with the perspective of non-participating owners, for whom financial incentives are either not a factor or one of many factors that dictate program participation:

"I paid cash for the property so there's really no incentive for me. I'm not looking to make money off it. It's just a piece of recreational property for myself. I wouldn't be interested in enrolling in a CFA, QFA, any other acronym you can come up with. I just want to have a place that's mine and I can know when I go there ... (and) take my kids out hunting. I have a spot no one's going to come and disturb us (at) and that kind of stuff."

"If somebody had it all worked out and they could show that it had been profitable, not only profitable but good for the earth or good for, you know, the forest or something, I could listen to it and see or not (whether enrolling property in a VIP made sense)." 


\subsection{Inadequate and Ineffective Outreach to NIPF Owners}

Inadequate funding and staffing can also reduce the ability of VIPs to reach all potential NIPF owners, particularly if program managers opt to use passive communication to disseminate information to potential participants as a way to conserve scarce resources. This illustrates a second key trait of street level bureaucrats; they have considerable discretion regarding how resources are allocated and how programs are managed, and this discretion directly influences policy implementation effectiveness $[16,17,22,25,26]$. Information about VIPs and natural resource agencies is disseminated at the discretion of program managers, and the passive nature of the information campaign exacerbates VIP enrollment problems:

“(P)robably the biggest obstacle is people not knowing about what we do. ( . . ) Sometimes they don't even know our agency exists even though there's websites out there; there's a Michigan NRCS (Natural Resource Conservation Service) website, there's a federal website and we have brochures and all kinds of stuff."

The lack of funding for outreach was frequently cited as the most important reason for low VIP enrollment rates. This problem forced managers to opt for economically efficient but passive outreach methods, such as mass e-mailings or broadcasting program information through a website. These methods were usually quite ineffective unless the program was able to first generate program interest indirectly through word-of-mouth, which often worked best for already popular programs like the Commercial Forest Reserve:

"We do not advertise or try and recruit landowners at all. A large number of our landowners come to (the Commercial Forest Reserve) because they have purchased a parcel that's already in the program. So that's one of the main entry points. (W)hen I just get a cold call and somebody's (... ) calling because they heard about the program and they want details about it, it's generally driven by (wanting) to save money on their taxes. They're not coming because, "Gee I want to manage my forest land, what can I do." It's "Oh my god I just got my tax bill and this can help." (Those are) kind of the (...) main ways that people come into the system. (W)e do not actively recruit landowners."

Interestingly, passive recruitment was a preferred outreach method for many program managers even if it reduced enrollment rates. Program managers feared that recruitment success would be paradoxically detrimental to the program, as the following two quotes demonstrate:

"If there's really no money in the program and we advertise, (and) a hundred people come in and only two get funded, you get a lot of negative publicity."

"I don't know if we have enough conservation district foresters. I don't know if we have enough qualified plan writers. (... ) That is one possible barrier to working with private landowners, that we cannot provide the services that they ask for because we're budget limited."

Nearly all program managers expressed a concern about being short staffed and administratively incapable of fulfilling program goals adequately. This then creates perverse incentives for program managers to, in some cases, intentionally handicap recruitment efforts to avoid "overselling" their program. These actions generate a feedback loop resulting in a self-fulfilling prophesy of low enrollment justifying even less funding, making it impossible to increase future enrollment. To add to this problem, program managers also believed that NIPF owners lack the ability to make well-informed decisions about VIP participation, due to information overload and too many competing programs:

"You know, one of the biggest barriers is just simply the amount of assistance that's available ... from a large number of players. And to your average Joe Public, who thinks that anybody who manages forests is in the Forest Service... No matter what agency or organization you belong to 
it's very overwhelming. Asking the public to try to wade through what they can find on the internet and ... (find) reliable sources, but still (the information is) very disjointed. So I think the biggest barrier that I've seen (is) a lack (...) of cohesion of all the agencies working together state wide to really make a simple concise message."

When asked how they learned about VIPs or collected management information, NIPF owners provided a very wide range of answers, from passive mailings to internet searches, and from informal discussions with friends to formal discussions with program managers. Additionally, several forest owners with enrolled property desired more information (especially on program changes) than they had been getting:

"They've had some rule changes (in the CFA) that I haven't been aware of at times, and I think that they could get out there and get those out to the owners a little bit more expedited because you don't find out or know unless you are on their website every day, or in the office every day. I think there should be a periodical. And I don't know how vast the individual ownerships are, but they're not (so) vast that they couldn't pop in the mail ... a letter that says, this has changed, this has changed, and this has changed. And little things change, not big things, but little things do."

"They quit sending them (newsletters about a thinning program for Commercial Forests). I don't know why. This was not from the Forest Service, it was from the USDA."

"I'd probably just go to the federal forestry if I wanted some information (about VIPs)."

"(We hear about programs) talking to neighbors and things like that, whatever it is. So it's word of mouth or whatever it is. We don't really participate (in them)."

"If I knew that there were some voluntary programs, you know, I would obviously go to Google."

"I pretty much can handle my own affairs pretty well. Some of this stuff ... (is) an opinion, so... they would maybe recommend that you chip something versus selective logging and you know that should be my decision. Like I say, the help that I need (to make land management decisions), it's nice to pull it up on the internet and in $10 \mathrm{~min}$, done."

A few landowners did directly contact program agencies for specific management advice, but not for information regarding VIPs:

"I've been really pretty much staying with the Forest Service, because the Forest Service ... because they have a list (for invasive species). Matter of fact one of the paulownia, I think it's Tomata paulownia tree is ... consider(ed) ... invasive, so I stayed away from that, these two (other tree species) aren't invasive."

"I suppose, if I didn't know any of those things (specifics about management practices such as clear cutting) I would probably just call the DNR office, or forestry office, or something. Or like I said, (local private forester) seems to know a lot about that stuff around here."

"I inquire, for example, I'll inquire with state foresters. There's a disease I believe going through ... a certain area, I heard there's six sections, (and) I don't know if they're infected with oak wilt. I own probably sixty acres of oak trees, I'll inquire with the state foresters, (on) what's going on, what's happening, what kind of disease is this. You know the spruce budworm is going through as well, killing the spruce trees. I'll inquire about that, but it's really limited contact with these organizations." 


\subsection{Regulatory Complexity}

Program managers and VIP advocates also often find themselves perplexed by existing regulatory confusion, as noted in the following quote:

"The other barrier I had was just the knowledge that I needed to gain about all these programs. You know the list is extensive as to conservation programs, as to tax incentive programs and the laws are extensive as well. When the new Qualified Forest bill was introduced, you know that's a legislative and a house bill that's three inches thick. So it's kinda my job to read through some of that, and learn what it is and learn how to convey that to the public as well. That's been a big barrier for me too, just learning everything that's out there, and how I can best use everything that's out there too."

The issue of confusing regulations was also echoed by several forest owners, describing the widespread misconceptions of how incentives such as tax breaks work in VIPs, or the VIP eligibility rules for a wetland mitigation banking program:

"I can go into the ad valorem tax situation. I think the misconception people have locally and maybe all around, is that, when a property gets put under commercial forest that the local municipality isn't getting paid any more than they are. So your forty seven dollars or whatever, they see that, but they don't understand that the State of Michigan is making up for that. Meaning that your community, or your county, or your local municipality is getting it as a payment in lieu of taxes from the state, so no one is missing out on tax money because somebody puts a piece of property under commercial forest. And that's the most important aspect to get out there to people."

"I've actually tried federal programs as well. Tried to get in on wetland mitigation and stuff like that. But we are a very obscure place here that nobody cares about, so the value of our wetlands is so much less (and are therefore usually not eligible for wetland mitigation programs)."

\subsection{Anti-Government Sentiment and the Role of Trusted Proxies}

Street-level bureaucrats do not operate in isolation, but rather are embedded in a complex social and political network containing many intermediaries and various levels of trust, directly influencing whether and how these bureaucrats implement policy $[17,27]$. Distrust of government officials (particularly regarding the risk of added regulatory burden) is a common dilemma for VIPs in our case study. One point of consensus across all interviewees was the awareness of a high level of distrust of government agencies, particularly state and local agencies and agents headquartered in the state capitol (Lansing). Program managers were very aware of the potential to dissuade otherwise-interested landowners in VIPs simply by their agency status. This distrust stems mainly from a fear of exposure to additional regulations or restrictions (a regulatory "Trojan Horse" [27], or suspicion regarding program manager or their proxy's true motives.

"People really mistrust the government... It's really hard to convince people that we're not up to something. People think they're going to end up paying some price for participating in these programs. They want to know 'quote unquote' when we're going to take control of their land. (T)hey don't believe us when we tell them that the money is no strings attached, that the management plans are voluntary."

"(Protecting the habitat of wolves was) actually part of (the founding legislation for our program) which ended up having complications for us down the road because wolves are extremely unpopular up here. (W)hen it was revealed that management was actually benefiting the wolves, but it benefits everything, the detractors used it as a pretty heavy stick against us."

Forest owners corroborated this belief: 
"I absolutely stay away from any of that because I don't want to have somebody come in and say, "Oh, you have this and this is what you should do." Then I get a deal that says if you touch anything you've got to get a permit. So I don't even let them come on the land."

"I'm really against, if it comes to the point where you have to go through a forester to manage your own land."

"I'm kind of hesitant for those kind of programs (VIPs) because I don't like to be regulated."

"The big one for me... I don't know exactly how Michigan works, but like in Wisconsin if you put your property in a forest management (plan) where they come and tell you which trees and stuff that you've got to cut... but a lot of that you can only keep out like an acre or maybe two acres and then you can't do anything else with your property. You can't build anything, you're stuck with that for the next twenty some years. And to me, if I decided I wanted to put a shed out in a particular spot and then you can't do it, you're just kind of stuck there for the next twenty years."

\subsection{Intent of Program Managers and Proxies}

The importance of a socially embedded, trusted, local intermediary has also been found to be important for programs for farmers [27]. Trust is a critical component in programs for private landowners in many countries, and in many contexts e.g., [27,28]. Conversely, distrust in the motives of either program managers or proxies who are seen to have too close a relationship with managers are likely to turn owners off to VIPs. When answering our question about whether a forest owner would enroll in a VIP based on the advice of either an agency representative or a proxy (such as a private forester), one forest owner responded: "That's what you find out when you get into some of these programs, it's all about money, and somebody wants to make money off you."

This turn to proxies (or other agents in social networks of street-level bureaucrats and participants) to drive VIP enrollment was supported both by our NIPF owner interviews [22] and the literature $[17,27,29]$. Proxies or intermediaries were more likely to be trusted by Western UP forest owners, particularly if they were locally active foresters, family, or neighbors.

"My neighbor at that property is a retired forester... I've talked to him ... about proper forest management."

"My forester friends, which are, I have some very very very good forester friends. They're only a phone call away. Very knowledgeable."

Proxies for government officials also helped to overcome the barrier of distrust in government:

"(Consultants) don't have the burden of being the authoritative agency ... (W)e have the authority.

We are the agency that can write tickets. So people don't like the DNR to come out on their property...

So, if we can provide (consultants) with guidance on what we think are relevant issues, they can be the translator for us to get the foot in the door and work with the landowners."

This puts consultants in a direct position to assist NIPF owners in overcoming the confusion generated by many VIP choices. They play a key role in determining what information is shared and how it is interpreted. This can have a huge impact on owner interpretations of VIPs and create or reinforce misinformation that is detrimental to their cause.

\subsection{Underserved Forest Owner Goals}

The prevailing culture of the Western UP often places some VIPs at an advantage over others, regardless of NIPF owner's goals. Program managers were aware that the current suite of VIPs in the state were mainly serving those owners who were primarily interested in harvesting and economic values, and owners with other management goals such as wildlife, aesthetics, or cultural heritage are underserved [22]. One program manager stated: 
"(O)ne thing that I've noticed... because I was a consulting forester before this...is that (most of) the landowners that call us (...) are interested in wildlife habitat management. My guess would be $70 \%$ of them. Not that they're not interested in timber, but it's wildlife. Sometimes they'll harvest timber to reach their wildlife goals."

Programs with a timber production focus, like the Commercial Forest Reserve, thrive in these conditions because they align well with the management goals of consultants who directly filter much of the information that reaches NIPF owners. On the other hand, wildlife and/or conservation programs, like the Landowner Incentive Program, not only struggle to connect with NIPF owners but also the general public who could persuade politicians to alter their funding decisions. Our work confirms the findings of other studies on the topic that have also found wildlife goals to be common among NIPF owners, and that these owners do enroll in VIPs where available [30].

Given adequate funding and/or better inter-program coordination, program managers could better connect NIPF owners to existing programs and provide the necessary services for programs to succeed. Lacking funds, programs are often required to contract out critical outreach and technical services to proxies, such as professional loggers or private consulting foresters, whose priorities often conflict with certain programs, as described in the following quote:

"(T)here has been a lot of friction between some of the consultants thinking that conservation districts are taking work away from them or that we were (... ) providing the work to landowners at no cost. So the initial barrier was to try and get past that."

Conservation oriented VIPs, like the Landowner Incentive Program, faced this problem more often than programs designed to stimulate timber harvesting, like the Commercial Forest Reserve, because it was assumed the former would only reduce profit-making opportunities while the latter would increase them. Yet, all VIPs regardless of their management goal relied heavily on these consultants to bring attention to their program because these were the individuals most likely to come into direct contact with NIPF owners.

\section{Conclusions}

Our findings align with prior research conducted in other areas of the US with high concentrations of NIPF owners, that inadequate funding for VIP implementation, poor outreach, and the consequent lack of awareness of VIP programs are major drivers of low VIP enrollment [8,31,32]. However, prior research has also concluded that VIP program managers and state officials assume financial incentives are the most important driver of program enrollment [8,33-35], and thus the best use of additional program funds is to "buy" more program participants, rather than reallocate resources towards information dissemination about these programs.

Our research comes to a different conclusion. In interviews of a purposeful sample of Western UP NIPF owners, we found that financial costs and benefits are not the only factors involved in forest management decisions [22]. Many of the NIPF owners we interviewed valued the cultural or heritage characteristics of their forests, suggesting that incentives geared towards plans which emphasize these forest values would be quite successful, especially if promoted by properly incentivized consulting foresters (perhaps by using an agglomeration bonus for landowners [36], with a commission fee for the forester) [22]. Heritage-based programs may need to be administered by agencies that do not have experience with VIPs for private land management (e.g., the Historical Society of Michigan), and thus some advice and coordination with more traditional land management agencies may be warranted. Land trusts (such as the Keweenaw Land Trust in the study region) may also provide flexible management advice to NIPF owners without activating their fear of potential regulatory action. These programs may also have different requirements for a forest management plan developed by a professional forester, as foresters typically do not have training for managing cultural or heritage-based amenities. 
Another incentive option might be structured on a payment for an ecosystem services program, which generated some interest among Wisconsin NIPF owners [37]. Policy implementation of ecosystem services-based programs by street-level bureaucrats may unfold similarly to the voluntary agri-environmental programs in Europe, where program managers utilize trusted local intermediaries to communicate and implement these policies to a far greater extent than the program managers interviewed here $[10,28,29]$. However, our program managers did not seem aware of these possibilities. Ultimately, we recommend that program managers modify incentives in ways other than simply increasing the financial reward of enrollment, which often amounts to simply an additional reduction in property taxes for the owner while further depleting necessary public revenues. Conservation programs in particular could do much more to use the scarce resources available to them to take advantage of public support for conserving cultural values in ways that popular programs like the Commercial Forest Reserve already do.

There are ways to address many of the problems identified in this paper without the need for massive reallocations of public funds. For example, the pervasive miscommunication between NIPF owners and program managers regarding VIP eligibility, goals, and land use restrictions suggests that a lack of communication is a key weakness of the current system. The importance of functional communication between program managers and policy targets has been identified for many policy classes [10,38-40]. There is an emerging consensus that peer-to-peer interaction may be a more efficient way to induce NIPF owner enrollment [41-43]. At the moment, most Western UP VIPs depend upon consultants to play a bridging role between the program agency and the NIPF owners, which only connects owners to programs that match the needs of the consultant. This leaves the vast majority of NIPF owners whose management intentions are conservation-oriented disconnected from the programs that would best suit their needs. It also does little to address the problems of information overload and misinformation that persist in the area (nor does it dampen the pervasive anti-government sentiment). Supplementing consultants with other community opinion leaders with conservation-oriented values is likely to significantly boost enrollment rates. Increased enrollment may then justify the funding increases necessary to sustain or expand program enrollment through more active outreach and program services than are currently feasible.

We believe that the findings reported in this paper provide an important contribution to the study of VIPs and their impact on NIPF owner land management activities. However, it is also important to note that the findings of this study may be limited to our geographic region. Given that our research method relied on interviews with a small number of purposively selected NIPF owners, the views presented in this study may not represent the wider NIPF owner population. The qualitative exploratory study presented here greatly strengthens our ability to investigate VIP enrollment more broadly and more effectively from the quantitative perspective in the future through landowner surveys. We recognize that even this future survey work will still be context dependent, and we encourage more exploratory and explanatory work which compares the perspectives of NIPF owners and program managers in other regions and for other policy areas. The problems of VIP enrollment and NIPF management coordination are not likely to improve without informed, targeted improvements in communication and policy design, so it is imperative that this work continues in this and other regions.

Supplementary Materials: The following are available online at http://www.mdpi.com/1999-4907/7/9/199/s1, Interview Protocol, Interview Questions, and Theme and Code book.

Acknowledgments: This work was supported by NSF Award \#1251932 (PI: MDR). Interviews were conducted by Lauren Dupey, Jennifer Lind-Riehl., Margaret Morrison, and Gabriela Shirkey, and we are indebted to them for this work, as well as early input from Richelle Winkler. Anonymous reviewers provided excellent suggestions for improvement on a previous version of this manuscript.

Author Contributions: M.D.R and A.L.M. conceived and designed the study, J.F.L.-R. and M.A. performed data collection, all authors analyzed the data and wrote the paper.

Conflicts of Interest: The authors declare no conflict of interest. 


\section{References}

1. Odum, W.E. Environmental degradation and the tyranny of small decisions. BioScience 1982, 32, 728-729. [CrossRef]

2. Rapp, V. Dynamic Landscape Management; Science Update; USDA Forest Service Pacific Northwest Research Station: Portland, OR, USA, 2002; pp. 1-12.

3. Williams, J.W.; Jackson, S.T. Novel climates, no-analog communities, and ecological surprises. Front. Ecol. Environ. 2007, 5, 475-482. [CrossRef]

4. Wiens, J.A. Landscape ecology as a foundation for sustainable conservation. Landsc. Ecol. 2009, 24, 1053-1065. [CrossRef]

5. Pelosi, C.M.; Goulard, M.; Balent, G. The spatial scale mismatch between ecological processes and agricultural management: Do difficulties come from underlying theoretical frameworks? Agric. Ecosyst. Environ. 2010, 139, 455-462. [CrossRef]

6. Greig, L.A.; Marmorek, D.R.; Murray, C.; Robinson, D.C.E. Insight into enabling adaptive management. Ecol. Soc. 2013, 18, 24. [CrossRef]

7. Mastrangelo, M.E.; Weyland, F.; Villarino, S.H.; Barral, M.P.; Nahuelhual, L.; Laterra, P. Concepts and methods for landscape functionality and a unifying framework based on ecosystem services. Landsc. Ecol. 2014, 29, 345-358. [CrossRef]

8. Mayer, A.L.; Tikka, P.M. Biodiversity conservation incentive programs for privately owned forests. Environ. Sci. Policy 2006, 9, 614-625. [CrossRef]

9. Potoski, M.; Prakash, A. The regulation dilemma: Cooperation and conflict in environmental governance. Public Admin. Rev. 2004, 64, 152-163. [CrossRef]

10. Juntti, M.; Potter, C. Interpreting and reinterpreting agri-environmental policy: Communication, trust and knowledge in the implementation process. Sociol. Rural. 2002, 42, 215-232. [CrossRef]

11. Sorice, M.G.; Haider, F.; Conner, R.; Ditton, R.B. Incentive structure of private landowner participation in an endangered species conservation program. Conserv. Biol. 2011, 25, 587-596. [CrossRef] [PubMed]

12. Kauneckis, D.; York, A. An empirical evaluation of private landowner participation in voluntary forest conservation programs. Environ. Manag. 2009, 44, 468-484. [CrossRef] [PubMed]

13. Amacher, G.S.; Conway, M.C.; Sullivan, J. Econometric analyses of nonindustrial forest landowners: Is there anything left to study? J. For. Econ. 2003, 9, 137-164.

14. Silver, E.J.; Leahy, J.E.; Weiskiftel, A.R.; Noblet, C.L.; Kittredge, D.B. An evidence-based review of timber harvesting behavior among private woodland owners. J. For. 2015, 113, 490-499. [CrossRef]

15. York, A.M.; Janssen, M.A.; Carlson, L.A. Diversity of incentives for private forest landowners: An assessment of programs in Indiana, USA. Land Use Policy 2006, 23, 542-550. [CrossRef]

16. Lipsky, M. Street-Level Bureaucracy: Dilemmas of the Individual in Public Services; Russell Sage Foundation: New York, NY, USA, 1980.

17. Hupe, P.; Hill, M. Street-level bureaucracy and public accountability. Public Admin. 2007, 85, $279-299$. [CrossRef]

18. Mitsos, M. Western UPper Peninsula Forest Improvement District: Adding Value to a Working Landscape. In Forest Communities, Community Forests; Kusel, J., Adler, E., Eds.; Rowman and Littlefield Publishers: Lanham, MD, USA, 2003; pp. 207-220.

19. Jakes, P. Learning from the experience of others: Four forest landowner cooperatives share their stories. In Forestry Cooperatives: What Today's Resource Professionals Need to Know, Proceedings of a Satellite Conference, 18 November 2003; Gen Tech Rep. NC-266. Jakes, P., Ed.; US Department of Agriculture, Forest Service, North Central Forest Experiment Station: St. Paul, MN, USA, 2006; pp. 53-62.

20. Strauss, A.; Corbin, J. Basics of Qualitative Research: Techniques and Procedures for Developing Grounded Theory; Sage Publications: Thousand Oaks, CA, USA, 2007.

21. Turner, D.W. Qualitative Interview Design: A Practical Guide for Novice Investigators. Qual. Rep. 2010, 15, 754-760.

22. Lind-Riehl, J.; Jeltema, S.; Morrison, M.; Shirkey, G.; Mayer, A.L.; Rouleau, M.D.; Winkler, R. Family legacies and community networks shape private forest management. Land Use Policy 2015, 45, 95-102. [CrossRef]

23. Knoot, T.G.; Rickenbach, M. Forester networks: The intersection of private lands policy and collaborative capacity. Land Use Policy 2014, 38, 388-396. [CrossRef] 
24. Maynard-Moody, S.; Musheno, M. Cops, Teachers, Counselors: Stories from the Front Lines of Public Service; University of Michigan Press: Ann Arbor, MI, USA, 2003.

25. Trusty, T.; Cerveny, L.K. The role of discretion in recreation decision-making by resource professionals in the USDA Forest Service. J. Environ. Manag. 2012, 107, 114-123. [CrossRef]

26. Sevä, M.; Jagers, S.C. Inspecting environmental management from within: The role of street-level bureaucrats in environmental policy implementation. J. Environ. Manag. 2013, 128, 1060-1070. [CrossRef] [PubMed]

27. Mariola, M.J. Farmers, trust, and the market solution to water pollution: The role of social embeddedness in water quality trading. J. Rural Stud. 2012, 28, 577-589. [CrossRef]

28. Sutherland, L.A.; Mills, J.; Ingram, J.; Burton, R.J.F.; Dwyer, J.; Blackstock, K. Considering the source: Commercialisation and trust in agri-environmental information and advisory services in England. J. Environ. Manag. 2013, 118, 96-105. [CrossRef] [PubMed]

29. Siebert, R.; Toogood, M.; Knierim, A. Factors affecting European farmers' participation in biodiversity policies. Sociol. Rural. 2006, 46, 318-340. [CrossRef]

30. Kilgore, M.A.; Snyder, S.A.; Eryilmaz, D.; Markowski-Lindsay, M.A.; Butler, B.J.; Kittredge, D.B.; Catanzaro, P.F.; Hewes, J.H.; Andrejczyk, K. Assessing the relationship between different forms of landowner assistance and family forest owner behaviors and intentions. J. For. 2015, 113, 12-19. [CrossRef]

31. Erickson, D.L.; Ryan, R.L.; De Young, R. Woodlots in the rural landscape: Landowner motivations and management attitudes in a Michigan (USA) case study. Landsc. Urban Plan. 2002, 58, 101-112. [CrossRef]

32. Ma, Z.; Butler, B.J.; Kittredge, D.B.; Catanzaro, P. Factors associated with landowner involvement in forest conservation programs in the US: Implications for policy design and outreach. Land Use Policy 2012, 29, 53-61. [CrossRef]

33. Horne, P. Forest owners' acceptance of incentive based policy instruments in forest biodiversity conservation-A choice experiment based approach. Silva Fenn. 2006, 40, 169-178. [CrossRef]

34. Stern, S.M. Encouraging conservation on private lands: A behavioral analysis of financial incentives. Arizona Law Rev. 2006, 48, 1-43.

35. Jack, B.K.; Kousky, C.; Sims, K.R.E. Designing payments for ecosystem services: Lessons from previous experience with incentive-based mechanisms. Proc. Natl. Acad. Sci. USA 2008, 105, 9465-9470. [CrossRef] [PubMed]

36. Parkhurst, G.M.; Shogren, J.F.; Bastian, C.; Kivi, P.; Donner, J.; Smith, R.B.W. Agglomeration bonus: An incentive mechanism to reunite fragmented habitat for biodiversity conservation. Ecol. Econ. 2002, 41, 305-328. [CrossRef]

37. Knoot, T.G.; Rickenbach, M.; Silbernagel, K. Payments for Ecosystem Services: Will a new hook net more active family forest owners? J. For. 2015, 113, 210-218. [CrossRef]

38. Grin, J.; van de Graaf, H. Implementation as communicative action: An interpretive understanding of interactions between policy actors and target groups. Policy Sci. 1996, 29, 291-319. [CrossRef]

39. Pyysiäinen, J.; Vesala, K.M. Activating farmers: Uses of entrepreneurship discourse in the rhetoric of policy implementers. Discourse Commun. 2013, 7, 55-73. [CrossRef]

40. Simmons, R. Improvement and public service relationships: Cultural theory and institutional work. Public Admin. 2016. [CrossRef]

41. Ma, Z.; Kittredge, D.B.; Catanzano, P. Challenging the traditional forestry extension model: Insights from the Woods Forum Program in Massachusetts. Small Scale For. 2012, 11, 87-100. [CrossRef]

42. Kittredge, D.B.; Rickenbach, M.G.; Knoot, T.G.; Snellings, E.; Erazo, A. It's the network: How personal connections shape decisions about private forest use. North. J. Appl. For. 2013, 30, 67-74. [CrossRef]

43. Schubert, J.R.; Mayer, A.L. Peer influence of nonindustrial private forest owners in the Western UPper Peninsula of Michigan. Open J. For. 2012, 2, 147-155.

(C) 2016 by the authors; licensee MDPI, Basel, Switzerland. This article is an open access article distributed under the terms and conditions of the Creative Commons Attribution (CC-BY) license (http://creativecommons.org/licenses/by/4.0/). 